\section{A interpretação dos profissionais de saúde acerca das queixas de "nervos" no meio rural: uma aproximação ao problema das intoxicações por agrotóxicos}

\author{
Occupational exposure to pesticides \\ and health professionals' interpretation \\ of "nervousness" among rural residents
}

Yvonne Elsa Levigard 1

Brani Rozemberg 1,2
1 Escola Nacional de Saúde Pública, Fundação Oswaldo Cruz, Rio de Janeiro, Brasil.

2 Instituto de Pesquisa

Clínica Evandro Chagas, Fundação Oswaldo Cruz, Rio de Janeiro, Brasil.

Correspondência B. Rozemberg Departamento de Epidemiologia e Antropologia, Instituto de Pesquisa Clínica Evandro Chagas, Fundação Oswaldo Cruz. Av. Brasil 4365, Rio de Janeiro, $R J$ 21045-900, Brasil.

\section{Abstract}

Occupational exposure to pesticides has a strong impact on Public Health in Brazil, since the country is one of the world's largest pesticide consumers. Harm to the rural population is reflected in high pesticide poisoning and case-fatality rates. The present paper focuses on the perspective of health professionals working in districts 5 and 7 of the Municipality of Nova Friburgo, Rio de Janeiro State, in the Family Health Program, concerning rural residents' complaints of "nervousness", verifying (1) whether health professionals perceive a link between "nervousness" and symptoms of pesticide poisoning, (2) the implications of their understanding on the reporting of work-related illnesses, and (3) medication for "nervousness" (use of tranquilizers) as a potential factor of social accommodation (as occurs elsewhere in urban groups) and as a potential cause of dual poisoning among workers exposed to pesticides. The methodology included interviews, participant observation, field notes, and consultation of previous studies in the area. The study highlights health professionals' discourse in relation to the association between "nervousness" and pesticides. The authors discuss factors related to this perception and make several suggestions for future research.

Pesticides; Occupational Health; Agriculture; Pesticide Exposure
Introdução

O problema da exposição ocupacional aos agrotóxicos adquire uma dimensão de forte impacto no que diz respeito à Saúde Pública, uma vez que o Brasil situa-se entre os maiores consumidores mundiais destes produtos, o maior da América Latina. Com um vasto mercado de agrotóxicos, que compreende aproximadamente trezentos princípios ativos aplicados em duas mil fórmulas diferentes, o Brasil tornouse um importante pólo de aplicação da nova dinâmica de produção agrícola, conhecida como Revolução Verde. Do montante dessas substâncias químicas, somente $10 \%$ foram efetivamente submetidas a uma avaliação completa de riscos e $38 \%$ jamais sofreram qualquer avaliação 1 .

O desenvolvimento do capitalismo na agricultura brasileira ocorreu de tal forma que interferiu diretamente sobre o saber tradicional e o processo de trabalho rural, expropriando os pequenos produtores e transformando-os, na maioria dos casos, em assalariados. Aqueles lavradores que ainda detêm os meios de produção sofrem uma exploração indireta, por meio da dependência do crédito bancário e dos baixos preços oferecidos por seus produtos, que são fixados em função não dos custos de produção e, sim, de acordo com os preços urbanos e com a margem de lucro pré-fixada pelos intermediários agrícolas 2 . 
Benjamin et al. 3 , referindo-se à crise rural brasileira apontam, dentre outros aspectos, a desestruturação da policultura, que levou enormes contingentes de pequenos proprietários à ruína e ao deslocamento de trabalhadores rurais. Tais mudanças trouxeram conseqüências decisivas aos padrões de morbidade e de mortalidade das populações, onde se inclui um aumento significativo de ocorrência de doenças cardiovasculares e mentais em trabalhadores rurais, assim como de acidentes de trabalho com máquinas e com a exposição aos agrotóxicos 4 .

No universo dos problemas de saúde descritos pelos próprios trabalhadores rurais são freqüentes as queixas de nervoso 5,6,7, bem como vem ocorrendo nas sociedades contemporâneas como um todo ${ }^{8,9}$. O levantamento bibliográfico realizado revelou que o nervoso é uma categoria semântica plástica, que transcende os enquadres biomédicos ou psicopatológicos, abrangendo as relações entre a corporalidade e as dimensões da vida social, enlaçando manifestações pessoais e coletivas, ideológicas, religiosas e emocionais. A compreensão do modo como as vivências do nervoso são referidas no quotidiano possibilita estabelecer um elo entre as queixas individuais e as tensões sociais, assim como outros determinantes presentes na organização do trabalho, da saúde e do ambiente dos grupos que estão vivendo o problema.

Sem se distanciar da perspectiva acima exposta, que pretende evitar a redução de toda a complexidade da experiência e da expressão simbólica do nervoso atribuindo-lhe este ou aquele agente causal único, o presente trabalho teve como objetivo estudar a interpretação de profissionais de saúde sobre as queixas de nervos e suas possíveis relações com o adoecimento por uso de agrotóxicos no âmbito do trabalho rural.

A preocupação com este tema resultou da constatação de semelhanças entre o quadro vago e indefinido das queixas clínicas nos casos de intoxicação crônica 10,11, com aquelas queixas descritas como "problema de nervos" por agricultores 5 . Tal semelhança entre sinais e sintomas relativos aos dois temas pode ser evidenciada na Tabela 1.

Rastreando o indício de um nexo associativo entre esses dois grandes problemas de saúde pública, encontramos algumas evidências bibliográficas, como em Possas \& Trapé 4 (p. 16): “(...) os acidentes causados por agentes químicos referem-se apenas a casos agudos (...). [Os] casos crônicos que constituem a maior demanda nos serviços médicos (...) são pacientes com sintomatologia vaga, como cefaléia difusa, mal estar geral, epigastralgia, inapetência etc., que à primeira consulta são tratados como casos de verminose e anemia e, após a segunda e terceira consultas, são rotulados como 'psicos' ou 'nó cego' pelos chefes de turma, pois não conseguem trabalhar direito. Na verdade, são pacientes com intoxicação crônica, em sua maioria expostos a inseticidas".

Faria et al. 6 em um amplo estudo epidemiológico com trabalhadores rurais na Serra Gaúcha conseguiram demonstrar quantitativamente que "a intoxicação por agrotóxicos apresentou uma forte associação com transtornos psiquiátricos menores", denominação dada aos "problemas de nervosismo" ou "problemas de tristeza e desânimo em algum momento da vida".

Também o estudo epidemiológico de Amr et al. 12 (p. 195), realizado no Egito com aplicadores e formuladores de agrotóxicos, encontrou resultados similares, enfatizando " $a$ alta freqüência de distúrbios psiquiátricos nos grupos expostos, com diagnóstico predominante de neurose depressiva, cujos sintomas mais freqüentes eram a irritabilidade e a disfunção erétil". Yousefi 13, em relação ao problema da exposição ocupacional aos agrotóxicos na África do Sul, aponta, dentre outros agravos à saúde dos agricultores, os distúrbios de memória, cognição e pensamento, além de alterações da personalidade. Igualmente relevantes para o tema são as reportagens de Furtado 14 e de Girardi 15, que versam sobre o provável nexo entre a exposição aos agrotóxicos e casos de depressão e de suicídio entre agricultores que trabalham em plantações de fumo no Sul do país, e em plantações de morango e de batata em Minas Gerais. Preocupação semelhante relacionando agrotóxicos ao alto número de suicídios é expressa no estudo de Pickett et al. 16, realizado entre trabalhadores rurais canadenses.

O presente estudo, utilizando metodologia qualitativa foi norteado teoricamente pela contribuição relevante de autores do campo da antropologia, sobretudo Duarte 8 , evitando o âmbito circunscrito dos saberes psicológicos e psiquiátricos para compreender a questão das queixas do nervoso entre trabalhadores como fenômeno mais amplo, de múltiplas dimensões, cuja extensão abrange desde queixas somáticas até perturbações que influem no viver familiar e coletivo das pessoas.

O desenvolvimento do trabalho de campo nos levou a optar pelo tratamento da questão com base na interpretação que os profissionais do Programa Saúde da Família (PSF) atribuem às queixas de nervoso no meio rural, de modo a verificar se é estabelecido um elo entre as quei- 
Comparação entre sintomas e sinais descritos para o "problema de nervos" e para a intoxicação por agrotóxicos.

\begin{tabular}{|c|c|c|}
\hline $\begin{array}{l}\text { Manifestações de intoxicação } \\
\text { por agrotóxicos* }\end{array}$ & $\begin{array}{l}\text { Sintomas relatados por agricultores } \\
\text { para definir "problema de nervos" }\end{array}$ & $\begin{array}{l}\text { Sintomas relatados por agricultores } \\
\text { intoxicados por agrotóxicos }\end{array}$ \\
\hline $\begin{array}{l}\text { - Dor de cabeça } \\
\text { - Vertigens } \\
\text { - Falta de apetite } \\
\text { - Falta de forças } \\
\text { - Nervosismo } \\
\text { - Dificuldades para dormir }\end{array}$ & $\begin{array}{l}\text { - Zonzeira/tonteira/rotação/vista } \\
\text { - Não consegue dormir } \\
\text { - Fraqueza/cansaço/falta de forças } \\
\text { - Dor no corpo/corpo moído/ } \\
\text { corpo machucado } \\
\text { - Dor de cabeça/dor no cérebro } \\
\text { - Tormento na mente/vozes na } \\
\text { cabeça/"idéia leve" } \\
\text { - Quedas/desmaios/convulsões/ } \\
\text { perda de consciência } \\
\text { - Não consegue comer } \\
\text { - Vômito/nojo } \\
\text { - Disparo do coração/dor no coração }\end{array}$ & $\begin{array}{l}\text { - Tonteira } \\
\text { - Dor de cabeça } \\
\text { - Dor no corpo } \\
\text { - Visão turva } \\
\text { - Dor de coluna } \\
\text { - Dor de estômago } \\
\text { - Queimação } \\
\text { - Falta de ar } \\
\text { - Vômitos } \\
\text { - Dor nas juntas } \\
\text { - Infecção nos rins } \\
\text { - Urticária } \\
\text { - Tremores } \\
\text { - Cansaço } \\
\text { - Pressão alta } \\
\text { - Problemas de fígado }\end{array}$ \\
\hline
\end{tabular}

* Organização Pan-Americana da Saúde/Organização Mundial da Saúde 10.

** Rozemberg 5 .

$\star \star \star$ Castro 11

xas de nervoso e os possíveis sintomas de intoxicação, bem como a repercussão deste entendimento sobre as notificações de acidente de trabalho.

\section{Metodologia}

O trabalho de campo foi realizado no período de março a dezembro do ano 2000, no Município de Nova Friburgo, principal região agrícola do Estado do Rio de Janeiro. Esse município tem sido alvo de constantes pesquisas nas áreas de toxicologia e de saúde do trabalhador, devido à intensiva utilização de agrotóxicos nas lavouras e da conseqüente contaminação humana e ambiental 1,11,17,18.

O levantamento dos dados foi feito por meio de entrevistas semi-estruturadas com profissionais do PSF, tendo abrangido no cômputo final 15 profissionais: um psicólogo; duas auxiliares de enfermagem; dois agentes comunitários; duas enfermeiras; seis médicos; um proprietário, prático de farmácia e recém-eleito vereador; e um engenheiro agrônomo. Um dos médicos entrevistados era o coordenador do PSF. Foi realizado ainda o registro sistemático das palestras e mesas-redondas da I Semana de Saúde e Educação de São Pedro da Serra (24-30 de julho de 2000).
A pesquisa foi beneficiada também por uma etapa exploratória de campo para reconhecimento das rotinas da vida local e orientação do pesquisador, identificando espaços de atendimento médico, distâncias envolvidas, horários de ônibus etc. Abordamos informalmente 11 pessoas, oito em pontos de ônibus e três nos pontos de comércio das localidades. Tais conversas não estão sistematizadas no presente trabalho, mas serviram para familiarização com a linguagem e o ritmo da vida local, evidenciando impressões gerais de moradores sobre trabalho, saúde e as condições de atendimento de que dispõem.

Os profissionais de saúde entrevistados nesta pesquisa atendem na área circunscrita pelas comunidades do 5o Distrito (Lumiar, Rio Bonito, Cabeceira do Rio Bonito, Galdinópolis, Macaé de Cima, Rio Bonito de Baixo, Toca da Onça, Santiago e Pedra Riscada e Boa Esperança) e do 7o Distrito (São Pedro da Serra, Vargem Alta, Colonial 61, Vargem Alta de Baixo, Stucky, Benfica, Bocaina dos Blaudt). As equipes do PSF incluem, por distrito, um(a) médico(a), um(a) enfermeiro(a), um(a) auxiliar de enfermagem e um(a) agente comunitário de saúde da própria localidade. Algumas equipes contam, ainda, com um(a) psicólogo(a).

Considerando que o PSF foi implementado no Município de Nova Friburgo em outubro de 
1996, o tempo de incorporação dos entrevistados (os não moradores da região) variava aproximadamente de um a três anos e meio.

A análise qualitativa dos dados de entrevistas foi realizada de modo a criar categorias de análise sobre o tema principal, ou seja, sobre os diferentes níveis de tratamento que os profissionais do PSF dão à questão das queixas de nervoso em trabalhadores rurais. Cabe ressaltar que, na condução das entrevistas com os profissionais de saúde foram evitadas referências prévias da parte do entrevistador sobre o seu interesse em investigar o tema da intoxicação por agrotóxicos (Tabela 2).

\section{Resultados discutidos}

\section{As circunstâncias de vida}

dos trabalhadores da região

As áreas da região têm característica tipicamente rural. A terra é o centro de referência da economia e da cultura da população local. A agricultura é a principal atividade produtiva, envolvendo homens, mulheres e, também, as crianças no plantio e colheita de flores, inhame, feijão, milho, tomate, pimentão, hortaliças etc. Devido ao relevo da região, grande parte das lavouras está localizada em encostas, no alto das montanhas. As estradas são de terra, estreitas e sinuosas, sendo que os moradores contam com poucos ônibus para o seu deslocamento. De modo geral, as casas já têm abastecimento de água encanada, precariamente instalado pelos próprios moradores, mas carecem de fossas ou de um sistema de saneamento, sendo ainda freqüente e usual o despejo do esgoto diretamente nos rios.

No decorrer da última década algumas mudanças têm ocorrido naquela região, trazendo tanto benefícios quanto problemas para a população local. Talvez o maior benefício seja a ampliação da rede educacional, o que tem diminuído o índice de analfabetismo, que é muito alto, sobretudo nas pessoas acima de cinqüenta anos. Alguns fatores têm contribuído para a mudança no perfil ocupacional dos habitantes, tais como o fato de a região ter se transformado em pólo turístico, a desvalorização dos produtos agrícolas e, também, o projeto do Instituto Brasileiro do Meio Ambiente e dos Recursos Naturais Renováveis (IBAMA) de proteção da Mata Atlântica, que proíbe as plantações em determinadas áreas e tem multado agricultores já estabelecidos. Sá Rego 2 (p. 126), afirma que "o pequeno produtor, desestimulado com a produção agrícola e atraído pelos altos preços oferecidos, loteia e vende suas terras (...) perdendo suas áreas de trabalho, que se transformam em áreas de lazer ou de moradia, improdutivas".

$\mathrm{O}$ incremento da construção civil tem gerado o aumento da oferta de trabalho para os homens em atividades diversas como pedreiro, marceneiro, jardineiro e pintor. Também as mulheres têm deixado as lavouras e ido trabalhar no comércio ou nas pousadas e nas casas de veraneio como faxineiras. Alguns agricultores têm alugado ou vendido as suas terras, ou parte delas, para a construção de pousadas, bares e restaurantes. Isto tem gerado uma espécie de favelização em algumas localidades, já que as famílias tendem a se aglomerar, acomodando-se em terrenos cada vez mais reduzidos. As decisões sobre o uso e desmembramento das propriedades são ocasionadas por reveses financeiros ou decisões arbitrárias dos patriarcas, gerando alguns conflitos familiares quanto ao destino da região e das gerações futuras. A criação de gado está tornando-se cada vez mais freqüente, uma vez que os abatedouros clandestinos se multiplicam com a conivência da população.

\section{Problemas de saúde referidos}

As condições de trabalho têm determinado, ao longo do tempo, problemas de saúde bem definidos na população da região, dentre os quais encontram-se as lesões por esforço repetitivo e as doenças ósteo-musculares, as intoxicações por agrotóxicos, o alcoolismo, a depressão e a hipertensão. Há referências, também, ao aumento significativo de casos de câncer de mama, fígado e próstata.

A hipertensão é reportada pelos profissionais de saúde como sendo elevada em ambos os sexos, sendo que as mulheres ficam hipertensas mais cedo, geralmente na faixa dos trinta anos. A dieta gordurosa e salgada, o clima frio, a altitude, o uso de pílulas anticoncepcionais como método contraceptivo preferencial, a utilização de agrotóxicos nas lavouras, o alcoolismo e a depressão foram os fatores associados à etiologia da hipertensão.

As intoxicações por agrotóxicos, manifestadas pela diminuição das defesas imunológicas, da anemia, da impotência sexual masculina, da cefaléia, da insônia, de alterações da pressão arterial, de distimias (alterações do humor) e de distúrbios do comportamento (surtos psicóticos) são descritos como freqüentes entre os agricultores, determinando, por vezes, a proibição médica do trabalho na lavoura e a orientação para outro tipo de atividade profissional. 
- Quais são as principais queixas de saúde nas pessoas que são atendidas no ambulatório?

- Quais são as principais queixas de nervoso dos usuários?

- A que circunstâncias você considera estarem relacionadas as queixas de nervoso?

- Qual é a sua atitude diante destas queixas?

- (e, apenas após esgotadas as respostas anteriores:) Você pensa existir alguma associação entre as queixas dos pacientes e o uso de agrotóxicos?

\section{Agricultura e agrotóxicos}

O trabalho na terra (produção agrícola) está vinculado às relações sociais que estruturam a família, envolvendo valores e diferenciações de papéis e hierarquias. Faz parte do ethos masculino assumir diretamente a tarefa de sulfatar a terra sendo, portanto, os homens os que mais se intoxicam. Porém, a exposição aos agrotóxicos é generalizada. Merece destaque a situação dos agricultores que plantam flores, uma vez que suas casas situam-se no centro do terreno, ficando as famílias completamente expostas à aspersão do produto.

Segundo os médicos entrevistados, o veneno (agrotóxico) é um elemento que faz parte da vida dos agricultores, havendo entre eles a crença de que os agrotóxicos são indispensáveis à lavoura, de que sem eles não há colheita. Esta crença é produto de uma ideologia que vem sendo forjada desde a década de 70 , como parte de uma estratégia de dependência de longo alcance criada pelas multinacionais 19 . Múltiplos são os tentáculos desta estratégia, que insinua-se nas políticas agrícolas, na formação acadêmica dos agrônomos e na lógica de plantio dos agricultores. A sua reprodutibilidade ocorre em todas as instâncias discursivas 17, abrangendo conotações tanto científicas quanto do senso comum, evidenciando-se nas palavras do agricultor, do engenheiro agrônomo, da indústria química e por vezes dos próprios profissionais de saúde.

\section{A interpretação dos profissionais de saúde acerca do nervoso no meio rural}

As entrevistas com os profissionais do PSF permitiram apreender como principais problemas de saúde da população local a hipertensão arterial, as verminoses, as intoxicações por agrotóxicos, as manifestações de nervoso e as doenças músculo-esqueléticas, não necessariamente nesta ordem. O entrelaçamento destes agravos evidencia sua relação com os hábitos de vi- da e com os processos de trabalho e realça questões sociais, econômicas e ambientais.

No que tange mais especificamente ao tema das queixas de nervoso, observamos que no relato dos profissionais (13) há quase unanimidade na afirmação de que apesar da beleza e da calma da região, as pessoas são muito estressadas, muito nervosas. As intoxicações por agrotóxicos, a desvalorização econômica da atividade agrícola, a sobrecarga de trabalho, a perda progressiva da terra como referencial de vida, o cansaço com os grandes deslocamentos para o centro da cidade, o fechamento de fábricas no município e o conseqüente desemprego na área urbana, a falta de perspectiva para construir o futuro, o isolamento social, a insatisfação conjugal, a aculturação a valores diferentes daqueles do grupo de origem, e a falta de lazer, estão entre os determinantes apontados para as manifestações de nervoso nas comunidades. Esta constelação de causas é acrescida de outros fatores, onde a cultura e a consangüinidade entrelaçam-se.

Na expressão de uma médica (Dra. L.), há uma "endemia de depressão", que é percebida por muitos profissionais como estando em estreita relação com o uso de agrotóxicos, sobretudo nas comunidades onde a atividade econômica ainda é predominantemente agrícola. A médica acima mencionada diz, inclusive, ter uma "teoria" a respeito da depressão das pessoas da região, segundo a qual a causa fundamental é a exposição aos agrotóxicos, uma vez que "os homens vão à frente sulfatando e as mulheres (e também as crianças) vão atrás carregando a mangueira". Tal procedimento na sulfatação foi observado também em outras pesquisas realizadas nesta mesma região rural de Nova Friburgo 11,17.

Dentre os médicos entrevistados que trabalham nos postos de saúde (5), somente um não estabeleceu enfaticamente e espontaneamente esta relação entre nervoso e agrotóxicos. Nas palavras de um médico, as pessoas tornam-se deprimidas, enfraquecidas, “com o raciocínio 
lento, apáticas, caladas demais (...). O sistema nervoso vai murchando. As pessoas ficam debilitadas do ponto de vista motor (...). As células nervosas perdem a capacidade de fazer a sinapse (...). É um agrobroxante, porque o agricultor se torna impotente sexual, o que desarma a família. A esposa tem desejo, ele tem desejo, mas não consegue ter relações sexuais (...). Os rapazes ficam impotentes com vinte e poucos anos (...). Às vezes suportam saber que as mulheres arranjaram amante e não dizem nada para não desmanchar o casamento" (Dr. A).

Os profissionais entrevistados apontam ainda problemas como o alto índice de alcoolismo na população, principalmente masculina. Para os entrevistados, o álcool potencializa a intoxicação por agrotóxicos e vice-versa: "muitos casos de hipertensão, depressão e suicídio parecem estar relacionados ao uso de agrotóxicos. O alcoolismo, também (...). Os agrotóxicos dão muito problema de estômago. Aí as pessoas bebem para não sentir dor de estômago (...). Há depressão tanto em homens quanto em mulheres" (auxiliar de enfermagem R.).

Outra questão fundamental presente nos depoimentos diz respeito ao aumento de casos de suicídio, tal como mencionado por alguns autores 14,15,16: "o nível de suicídios é alarmante em toda a região da montanha (...) de Nova Friburgo, principalmente entre os homens, devido à aculturação, à falta de perspectiva de construir um futuro. Entram em depressão (...). Os suicídios são principalmente por envenenamento. Tomam desfolhante mesmo" (psicólogo).

"As pessoas vivem no limiar entre a apatia e a conduta violenta (...). Ocorrem crimes devido a condutas impulsivas (...). A depressão tem levado muitas pessoas ao suicídio. As pessoas se suicidam tomando desfolhante, agrotóxico" (Dr. A).

Dentre os profissionais de saúde entrevistados, dois médicos associaram as alterações bruscas de comportamento à exposição aos agrotóxicos. Segundo Weiss 20, a exposição aos agrotóxicos produz, dentre outros agravos, alterações no sistema endócrino, mais especificamente nos níveis do hormônio da tireóide, desencadeando déficit de atenção e/ou hiperatividade em crianças, assim como irritabilidade, alterações de humor e comportamento agressivo em adultos. $\mathrm{O}$ estudo assinala a gravidade do problema em relação às gestantes, cujos fetos são atingidos por estas alterações hormonais, o que repercute em seu desenvolvimento posterior.

De modo geral, os profissionais do PSF mostraram uma sensibilidade aguçada com relação às queixas de nervoso, expondo a sua preocupação com determinados processos de traba- lho e hábitos da população, assim como com a venda indiscriminada de calmantes em farmácias da região. No que concerne à questão ocupacional, observa-se na maioria dos relatos uma ênfase na exposição aos agrotóxicos, assim como nos múltiplos fatores que têm determinado mudanças nos papéis profissionais dos moradores das comunidades.

\section{A medicalização do nervoso}

Ainda que em nossa amostra de entrevistados tenhamos tido somente 6 médicos, é relevante lembrar que são eles que respondem pelo atendimento das 16 comunidades rurais de Nova Friburgo, cada uma delas composta por sua vez, de inúmeros "arraiais". Como vimos, os médicos entrevistados, com duas exceções, explicitaram espontaneamente seu ponto de vista de que pode haver associação entre as queixas de nervoso e a intoxicação por agrotóxicos. A maioria dos médicos entrevistados expôs sua preocupação em oferecer aos pacientes terapêuticas (fitoterápicos e vitaminas) e orientações (necessidade de caminhar, afastamento da atividade agrícola etc.) que possibilitassem a melhoria de suas condições pessoais, familiares e sociais, sem ter de recorrer às drogas de ação no sistema nervoso central. Somente dois médicos admitiram receitar sistematicamente psicofármacos para seus pacientes. Alguns médicos queixaram-se da dificuldade de tratar os que já fazem uso rotineiramente de todo tipo de medicação para o nervoso (neuroléticos, anticonvulsivantes e ansiolíticos), misturados e em dosagens aleatórias, com enorme prejuízo para sua saúde.

O problema do consumo de calmantes por parte da população revela uma situação delicada para muitos profissionais de saúde, sobretudo para os médicos. Apesar da resistência que a maioria dos médicos entrevistados manifestou com relação à prescrição de calmantes, estes são vendidos livremente, sem receita, em muitas farmácias, seja no povoado próximo, seja na cidade de Friburgo. O incremento do consumo de calmantes em regiões rurais, tal como ocorre nos centros urbanos, evidencia também um esquema perverso que transforma a doença em mercadoria e fonte de lucros 5,19.

Comprando remédios, as pessoas acreditam estar comprando "saúde", ou melhor, comprando um paliativo para a sua fraqueza, a sua fadiga, a sua dor, o seu inconformismo, os incômodos da vida 19. Mas, os remédios podem trazer efeitos opostos aos desejados, ou seja, podem traduzir-se em maior fraqueza, fadiga e incômodo, sobretudo naquelas pessoas que es- 
tão debilitadas pelos efeitos tóxicos dos produtos usados nas lavouras, como descrito por três dos médicos por nós entrevistados.

Assim como a pesquisa de Alves 18 constatou a utilização usual nas plantações do Município de Nova Friburgo de cem diferentes formulações de agrotóxicos, sem que haja, de modo geral, qualquer supervisão ou conselho técnico, encontramos a mesma tendência em relação ao uso de medicamentos. Um estudo entre agricultores constatou 26 marcas de fantasia de drogas de ação no sistema nervoso central sendo utilizadas por apenas 28 entrevistados 5 . Este incremento de interesses de mercado no campo, sem qualquer controle, vem gerando uma situação de alto risco, expondo trabalhadores já intoxicados por agrotóxicos a uma dupla intoxicação pelo uso de medicamentos.

\section{As atitudes e as contradições dos profissionais no atendimento à população}

No cômputo final, apenas 3 dos 15 entrevistados não fizeram associação entre as queixas de nervos e agrotóxicos, sendo uma enfermeira e dois médicos, um deles afastado em cargo político, não se ocupa mais diretamente de pacientes. Nossos resultados permitiram levantar alguns fatores que podem interferir no estabelecimento ou não do nexo associativo por parte dos profissionais entrevistados: (1) a proximidade ou o distanciamento da prática do atendimento às comunidades; (2) a abordagem desde uma perspectiva clínica ou desde uma perspectiva política; e (3) o tempo de permanência e a conseqüente familiaridade com o processo de trabalho agrícola que permitem constatar a epidemia de intoxicação por agrotóxicos, são alguns desses fatores. Eles fazem com que a discussão sobre as adversidades vividas pela população, e que são expressas no nervoso, ganhe relevância ou não no discurso dos profissionais.

A análise do material de campo permitiu perceber algumas contradições entre o discurso e a prática dos profissionais. Se, por um lado, a prática profissional os aproxima de uma compreensão da realidade local e de um movimento voltado para as necessidades expressas pelas comunidades, por outro, a internalização dos vieses funcionalistas da formação acadêmica, ela própria submetida a pressões do mercado, leva alguns profissionais a apresentarem um duplo discurso. Assim, um dos médicos entrevistados foi enfático em associar a sintomatologia de nervoso com o contexto de intoxicação por agrotóxicos, descrevendo perturbações diversas, e defendendo a necessidade de cons- cientizar os agricultores em relação a técnicas alternativas de plantio; criticou a livre comercialização de agrotóxicos e de calmantes. O relato de vários moradores revelou, porém, que a conduta terapêutica do referido médico consistia fundamentalmente na prescrição de grande quantidade de ansiolíticos, antidepressivos, neuroléticos etc, em oposição ao seu discurso. Esse episódio reforça a importância da triangulação metodológica, onde o conteúdo das entrevistas é relacionado e confrontado a outras fontes sobre o contexto estudado.

Constatamos que o foco das recomendações médicas, de modo geral, recai na mudança de comportamentos individuais. Além disso, deparamo-nos com o questionamento a respeito da eficácia de programas de educação e promoção em saúde dissociadas das representações sociais dos grupos aos quais destinam-se 21 .

\section{A naturalização do uso de agrotóxicos}

Uma primeira hipótese constatada neste estudo refere-se à naturalização do uso de agrotóxicos no meio rural brasileiro. Esta naturalização, no nível do discurso das pessoas que vivem na região e, também, dos profissionais que as atendem se traduz em uma interpretação dualista. Os agrotóxicos são percebidos naquele universo a partir de duas concepções antagônicas, ou seja, como remédio e como veneno, o que corrobora os estudos de Sá Rego 2, de Castro 11 e de Peres et al. 17. De modo geral, a justificativa para o uso destes produtos baseiase no estado de esgotamento em que se encontram os solos locais e na suscetibilidade cada vez maior à proliferação de pragas. É o "remédio" para garantir a produtividade das lavouras.

“O agrotóxico nada mais é do que um antibiótico para combater as pragas que atacam as lavouras (...). Cada lavoura tem o seu agrotóxico (...)" (Dr. D).

"O agrotóxico infelizmente ainda é necessário (...). Cada vez as sementes e as pragas estão mais resistentes (...). As intoxicações por agrotóxicos são o principal problema de saúde da população. É necessário, é imprescindível mudar a relação com o agrotóxico, uma vez que não dá para não usar agrotóxico (...)" (Dr. A).

Os profissionais que atendem a população são unânimes em afirmar a grande vulnerabilidade dos agricultores e de suas famílias aos agrotóxicos, uma vez que estes são utilizados de forma indiscriminada e sem os cuidados mais elementares de proteção.

Embora os estudos indiquem que a maioria dos casos de intoxicação por agrotóxicos ocor- 
ra, principalmente, devido ao descumprimento das normas de segurança para a sua aplicação, devido a irregularidades no armazenamento e na distribuição dos produtos, assim como à ausência de políticas públicas de controle 10 , gostaríamos de ressaltar que a focalização do problema estritamente no nível dos usuários acaba isentando a responsabilidade das indústrias que lucram com esta situação.

\section{Considerações finais e recomendações}

No cenário da dramática realidade de exposição dos trabalhadores rurais aos agrotóxicos, a associação entre queixas de nervoso e intoxicação mostrou-se reiteradamente presente no discurso dos profissionais de saúde da região, que por sua proximidade com a população tornam-se sensíveis às circunstâncias de vida e aos processos de trabalho. Alguns desses profissionais se incluem na população exposta aos agrotóxicos.

A convivência com a população das comunidades e com os agravos de seu quotidiano modificou o olhar desses profissionais, enriquecendo uma formação acadêmica, que de modo geral, é fortemente influenciada por interesses de mercado. Essa convivência abriulhes caminho para uma possibilidade interpretativa mais articulada com a realidade de vida das pessoas, provocando-os a assumir seu papel de sujeitos sócio-históricos-culturais, pressupondo uma ruptura com concepções e práticas que negam a sua compreensão. A maioria dos profissionais de saúde entrevistados fez referência à falta de um respaldo do conhecimento formal para o embasamento destas articulações construídas por meio da prática, além do acesso à bibliografia e aos meios de comunicação, como a Internet, dependente de linhas telefônicas, ausentes na região na época da realização desta pesquisa.

A complexidade que envolve a questão do uso de agrotóxicos na agricultura brasileira, insere-se em uma discussão mais ampla, relativa à necessidade de mudanças nas políticas agrícolas. Conforme vimos no decorrer deste estudo, a industrialização da agricultura no Brasil foi forjada, dentre outras coisas, a partir da utilização em grande escala de insumos químicos, sob a pressão econômica de poderosos grupos multinacionais, que têm em nosso país um de seus maiores mercados consumidores. Essa pressão econômica "modernizadora” atingiu diretamente os agricultores, contrastando com o seu saber tradicional e alterando a sua lógica de plantio. O círculo vicioso que se estabeleceu com o esgotamento dos solos e com o aumento da resistência às pragas, tornou os agricultores cada vez mais dependentes da aplicação de produtos químicos em suas terras e plantações. Existem nos dias atuais algumas iniciativas bem sucedidas de agricultores organizados em torno da agricultura orgânica, mas ainda é grande a vulnerabilidade por parte do agricultor ou do grupo de agricultores que tentam prescindir do uso de agrotóxicos.

São imprescindíveis estudos sobre a maneira como profissionais de instituições de saúde das áreas urbanas lidam com as queixas de nervoso de trabalhadores oriundos das áreas rurais onde há exposição a agrotóxicos, uma vez que nossos dados apontam para o fato de que o distanciamento da prática de atendimento em meio rural parece ser um fator de alienação desta questão. A não observância do possível nexo associativo traz o risco da dupla intoxicação devido à interação de substâncias tóxicas diversas (agrotóxicos e medicamentos). Neste sentido, é fundamental a utilização por parte dos profissionais de saúde, que atendem a população rural, de instrumentos de notificação 10 .

A desatenção relativa ao nexo entre os processos de trabalho e de saúde/doença, observada com freqüência nas instituições de saúde é um dos reflexos da lógica espoliativa, de pouca valorização do trabalhador, que permeia o desenvolvimento econômico da sociedade brasileira. Tal lógica perpassa os ensinamentos acadêmicos e insinua-se nas práticas profissionais. Este é um dos motivos que explica o fato de a história ocupacional não ser percebida como parte da história de vida dos sujeitos que buscam atendimento. Nos prontuários, os dados relativos à "profissão" ou "ocupação" são, via de regra, dados burocraticamente registrados, à exceção dos casos de acidentes de trabalho, onde muitas vezes o acidentado ainda é responsabilizado pelo agravo sofrido. No caso específico das instituições psiquiátricas, onde as queixas dos pacientes nem sempre apresentam "evidências" por meio de exames, as chances de profissionais buscarem estabelecer o nexo entre as queixas de nervoso e os processos de trabalho são ainda menores.

Finalmente, tendo em vista esta elevada subnotificação do problema no país, uma proposta possível com base na abordagem territorial que permeia o modelo assistencial do SUS e, conseqüentemente, do PSF, seria a da que se considerasse a hipótese de intoxicação para agricultores expostos a agrotóxicos, que estejam apresentando queixas de nervoso (irritabilidade, insônia, depressão etc.). 
A consideração da hipótese de intoxicação não significaria a redução da experiência de nervos a um agente causal único, mas o reconhecimento de que se trata de ocorrência freqüente neste grupo ocupacional, requerendo investigação diferenciada.

Considerando a complexidade da expressão simbólica do "nervoso", cujas manifestações só adquirem significado a partir da ótica dos grupos que estão vivendo o problema, as reflexões apresentadas evidenciam a necessidade de articulação entre os setores de saúde, educação, trabalho e agricultura, assim como a importância da escuta dos trabalhadores, de modo a conhecer sua interpretação a respeito da realidade em que vivem.

\section{Resumo}

O problema da exposição ocupacional aos agrotóxicos adquire uma dimensão de forte impacto no que diz respeito à Saúde Pública, uma vez que o Brasil situase entre os maiores consumidores mundiais de agrotóxicos. O presente trabalho focaliza a interpretação que os profissionais do Programa Saúde da Família, atuantes no 5 o e no 7 o distritos do Município de Nova Friburgo, Rio de Janeiro, atribuem às queixas de nervoso no meio rural, de modo a verificar (1) se é estabelecido um elo entre as manifestações de nervoso e os sintomas de intoxicação, (2) de verificar a repercussão deste entendimento sobre as notificações de acidente de trabalho, (3) assim como de discutir a medicalização do nervoso (uso de calmantes) como possivvel fator de acomodação social, tal como ocorre nos grupos urbanos, e como possível desencadeador de uma dupla intoxicação nos trabalhadores expostos a agrotóxicos. Foram realizadas entrevistas, observações, anotações de campo e levantamento de pesquisas realizadas na área. Destaca-se no discurso dos profissionais a associação entre as queixas de nervos e a exposição a agrotóxicos, sendo discutidos os fatores a isso relacionados e esboçadas algumas recomendações para futuras investigações.

Agrotóxicos; Saúde Ocupacional; Agricultura; Exposição a Praguicidas

\section{Colaboradores}

$\mathrm{O}$ artigo foi redigido conjuntamente pelas autoras. 


\section{Referências}

1. Meirelles LC. Controle de agrotóxicos: estudo de caso do Estado do Rio de Janeiro, 1985/1995 [Dissertação de Mestrado]. Rio de Janeiro: Instituto Alberto Luiz Coimbra de Pós-graduação e Pesquisa de Engenharia, Universidade Federal do Rio de Janeiro; 1995.

2. Sá Rego VVB. Mundos em confronto: o desenvolvimento do capitalismo e a educação numa comunidade camponesa [Dissertação de Mestrado]. Rio de Janeiro: Departamento de Educação, Pontifícia Universidade Católica; 1988.

3. Benjamin C, Alberti AJ, Sader E, Stédile JP, Albino J, Camini L, et al. A opção brasileira. Rio de Janeiro: Editora Contraponto; 1998.

4. Possas CA, Trapé AZ. Saúde e trabalho no campo: da questão agrária à política previdenciária. Cadernos do Internato Rural 1983; 2:13-9.

5. Rozemberg B. O consumo de calmantes e o "problema de nervos" entre lavradores. Rev Saúde Pública 1994; 28:300-8.

6. Faria NMX, Facchini AA, Fassa AG, Tomasi E. Estudo transversal sobre saúde mental de agricultores da Serra Gaúcha. Cad Saúde Pública 2000; 16:115-28.

7. Gomes AA, Rozemberg B. Condições de Vida e Saúde Mental na Zona Rural de Nova Friburgo RJ. Psicologia Ciência e Profissão 2000; (4):16-29.

8. Duarte LFD. Da vida nervosa nas classes trabalhadoras urbanas. Rio de Janeiro: Editora Zahar; 1988.

9. Davis DL, Guarnaccia PJ. Health, culture and the nature of nerves. introduction. Med Anthropol 1989; 11:1-13.

10. Organização Pan-Americana da Saúde/Organização Mundial da Saúde. Manual de vigilância da saúde de populações expostas a agrotóxicos Brasília: Organização Pan-Americana da Saúde/Organização Mundial da Saúde; 1996.

11. Castro JSM. Práticas de uso de agrotóxicos no município de Cachoeiras de Macacu, Rio de Janeiro - um estudo ambiental [Dissertação de Mestrado]. Niterói: Universidade Federal Fluminense; 1999.
12. Amr MM, Halim ZS, Moussa SS. Psychiatric disorders among Egyptian pesticide applicators and formulators. Environ Res 1997; 73:193-9.

13. Yousefi VO. Agrochemicals in South Africa. African Newsletter on Occupational Health and Safety 1999; 9:56-67.

14. Furtado T. Química do suicídio. Atenção Brasil 1998; 6:32-4.

15. Girardi G. A última colheita. Revista Galileu 2002; 133:24-31.

16. Pickett W, King WD, Lees RE, Morrison HI, Brison RJ. Suicide mortality and pesticide use among Canadian farmers. Am J Ind Med 1998; 34:364-72.

17. Peres F, Rozemberg B, Moreira J, Rabello S. O processo de comunicação sobre agrotóxicos em área rural do Estado do Rio de Janeiro. Rev Saúde Pública 2001; 35:21-37.

18. Alves SR. Avaliação dos resíduos de pesticidas organofosforados e carbamatos por metodologia enzimática no córrego de São Lourenço, Nova Friburgo - RJ, Brasil [Dissertação de Mestrado]. Rio de Janeiro: Escola Nacional de Saúde Pública, Fundação Oswaldo Cruz; 2000.

19. Chiavenato JJ. O massacre da natureza. São Paulo: Editora Moderna; 1991.

20. Weiss B. Crime times concerns raised about pesticides' effects. Research Reviews and Information on Biological Causes of Criminal, Violent and Psychopathic Behavior 1998; 4:1-4.

21. Rozemberg B, Peres F. Reflexões sobre a educação relacionada aos agrotóxicos em comunidades rurais. In: Peres F, Moreira JC, organizadores. É veneno ou é remédio? Agrotóxicos, saúde e ambiente. Rio de Janeiro: Editora Fiocruz; 2003. p. 367-84.

Recebido em 23/Dez/2003

Versão final reapresentada em 03/Jun/2004 Aprovado em 22/Jun/2004 